NBER WORKING PAPER SERIES

\title{
LIFE-CYCLE LABOR FORCE PARTICIPATION OF MARRIED WOMEN: HISTORICAL EVIDENCE \\ AND IMPLICATIONS
}

\author{
Claudia Goldin
}

Working Paper No. 1251

NATIONAL BUREAU OF ECONOMIC RESEARCH 1050 Massachusetts Avenue

Cambridge, MA 02138

December 1983

This research has been supported by a grant from the National Science Foundation. The comments of Robert Margo and Paul Taubman are gratefully acknowledged. The research reported here is part of the NBER's research program in Development of the American Economy. Any opinions expressed are those of the author and not those of the National Bureau of Economic Research. 
NBER Working Paper \# 1251

December 1983

Life-Cycle Labor Force Participation of Married Women:

Historical Evidence and Implications

\begin{abstract}
The five-fold increase in the labor force participation rate of married women over the last half century was not accompanied by a substantial increase in the average job market experience of working women. Two data sets giving life-cycle labor force histories for cohorts of women born from the $1880 \mathrm{~s}$ to $1910 \mathrm{~s}$ indicate substantial (unconditional) heterogeneity in labor force participation. Married women in the labor force had a high degree of attachment to it; increased participation rates brought in women with little prior job experience and reduced cumulated years experience. According to extant schedules from a 1939 Women's Bureau Bulletin, 86\% of married women born around 1895 and working in 1939 had been employed 50\% of the years since beginning work, and $47 \%$ had worked $88 \%$ of those years. Average years of experience for cross sections of working married women hardly increased from 1920 to 1950, rising from 9 to 10.5 years. Because wages are calculated only for currently employed individuals, the steadiness in relative wages of women to men over this period may result from stable experience ratings for employed married women. An exploration of the determinants of labor force persistence points to the importance of occupational choice early in the work history of a woman and to the rise in clerical and professional occupations in extending life-cycle labor force participation.
\end{abstract}

\author{
Claudia Goldin \\ Department of Economics \\ 3718 Locust Walk/CR \\ University of Pennsylvania \\ Philadelphia, PA 19104 \\ (215) 898-4489 (7733)
}


1.0 Introduction: Life-Cycle Labor Force Participation

The five-fold increase over the last half century in the labor force participation rate of married women might be expected to have been accompanied by a substantial increase in the average job market experience of working women. Surprising as it may seem, the data assembled here suggest that cumulated work experience for employed married women barely increased over most of this period. Life-cycle labor force participation provides the link between changes in static labor force participation rates and the experience rating of the working population.1

A longitudinal or life-cycle dimension to the participation rate is added here through the use of two sources containing retrospective information on cohorts considerably older than those covered by the two panel studies, the National Longitudinal Survey (NLS) and the Panel Study on Irscome Dynamics (PSID). The first of these sources is a 1939 Women's Bureau Bulletin, which contains what I believe to be the earliest retrospective information on life-cycle labor force participation for a large sample of married women.2 The second is a more familiar source, the Social security records linked to the Retirement History Survey.

These two sources confirm for an older group of female cohorts what has been found among more recent ones: Married women who are

\footnotetext{
1 The labor force participation rate is a static measure, giving the percentage of individuals working or seeking a job sometime in the week preceding the census, or, prior to 1940, the percentage who stated that they had an occupation during the census year.

2 The Women's Bureau was founded in 1920 as part of the Department of Labor.
} 
in the labor force have a high degree of attachment to it. Extant schedules from the 1939 Women's Bureau Bulletin indicate that among married women in the cohort born between 1891 and 1900 and in the labor force in 1939,86 percent had worked 50 percent of the years since beginning work and 47 percent had worked 88 percent of the years since beginning work. Among women not in the labor force in 1939 only 19 percent had worked 50 percent of the years since beginning work and merely 2 percent had worked 88 percent of the years. The determinants of labor force commitment are also explored with this data set. The Social Security Administration records tell a similar story: Among white married women in the cohort born 1906 to 1910 and in the labor force in 1953, 48 percent would eventually participate in the labor force almost 90 percent of the years covered in the data, those from 1951 to 1969.

Estimates of the experience rating of women employed within the years 1910 to 1980 and born between 1875 to 1925, are generated from these two sources. According to these estimates, the average years of experience for a cross section of working married women hardly increased from 1920 to 1950 (rising from about 9 years to 10.5 years) despite substantial increases in the labor force participation rate of this group. The estimates of labor force experience generated from these data are consistent with those produced for the period 1940 to 1980 (Smith and Ward 1983), although by a different technique.

The apparently anomalous findings concerning changes in labor force participation and cumulated experience owe to the substantial fraction of married women who stay in their present working state 
from year to year. Increases in the labor force participation rate increase the pool of working women and thus raise the experience rating of the entire population of women. But the experience rating of the working population will remain relatively constant, because those drawn into the labor force will have far lower experience ratings than those already working.

Because wages are calculated only for individuals who are currently employed, the steadiness in relative wages of women to men over this time period may result, at least in part, from rising labor force participation rates and thus stable experience ratings for employed married women. The absence of a positive relationship between relative wages and female labor force participation has puzzled many observers.

The organization of this paper is as follows. Section 2 derives analytical expressions for experience ratings under two extreme assumptions, "perfect homogeneity" and "perfect heterogeneity." Section 3 examines the life-cycle labor force participation data in the two surveys that span the half decade from 1920 to 1970 and analyzes some of the determinants of life-cycle labor force participation. Section 4 uses these data and the analytical expressions of Section 2 to derive estimates of experience ratings of the working female population from 1920 to 1950.

\subsection{Homogeneity vs. Heterogeneity of Female Labor Supply}

If the labor force participation rate of married women is, say, 40 percent, does it mean that 40 percent of all married women are always in the labor force, with the other 60 percent permanently out? Or does it mean that each woman is employed 40 percent of her life- 
time? The truth will certainly lie somewhere between these extremes, of homogeneity and heterogeneity, but the degree to tends to to one or the other will determine the accumulated labor force experience of working women and thus the wages women relative to those of men. 3

A population of women who are "perfectly homogeneous" with respect to labor supply will be defined as having identical probabilities of being in the labor force. If homogeneity is conditional on various characteristics, such as education and husband's income, women within these groups would have identical lifetime labor supply, except for the ex post realization of a draw from an identical distribution determining when employment will occur.4 If the labor force participation rate ( $I$ ) is interpreted as the probability a woman will be in the labor force that year and if it is unchanging with age, the average employment spell is the sum of the series $\{1 / L t\}, t=0, \ldots ., n$.

At the other extreme is the notion of heterogeneous labor supply. If the labor supply function is unchanging with age, women who are "perfectly heterogeneous" are "stayers," being either in or out of the labor force. In general, "perfectly heterogeneous" women remain in or out of the labor force consistent with the aggregate labor supply

\footnotetext{
3 Ben-Porath (1973) and Heckman and Willis (1977) posed the same questions.

4 Throughout this discussion the notions of heterogeneity and homogeneity will be made with reference to the unconditional probabilities of being in the labor force. See Heckman and Willis (1977) for a discussion of the conditional probabilities with reference to these concepts and their reply to Mincer and Ofek (1979), (Heckman and Willis, 1979), in which they discuss these concepts in unconditional terms. The conditional probabilities are relevant to interpreting the parameters from labor supply equations used to estimate income and substitution effects. The unconditional probabilities are relevant here to estimating experience ratings for the working population of women.
} 
data.5 If labor force participation increases over time, entrants are drawn into the labor force from the pool of women who have rarely or never yet been employed. When cohort participation rises with age, as it has in the United States, "perfect heterogeneity" implies that the highest labor force participation rate achieved by a cohort will be the maximum percentage of this cohort ever to be in the labor force, LMAX. Likewise [1-LMAX] is the percentage who will never be in the labor force over the life-cycle.

Mincer (1962, 1966) had assumed that the average female labor force participation rate for a cohort was the percentage of time a randomly selected woman in that cohort would work over her lifetime. Her life-cycle decisions, therefore, were to choose this percentage and then allocate it over time. Ben-Porath (1973) had questioned this logic in light of data in the 1960 Census suggesting that women who were not in the labor market in 1960 had worked very little during the decade before. "That is, even though these data do not refer to experience under static conditions, they indicate that a fair amount of current nonparticipation in the labor force represents "permanent" nonparticipation" (p. 701$)$.

The evidence that first prompted Ben-Porath to question the presumed notion of homogeneity was suggestive but weak. Considerably better data are now available, in both the NLS and the PSID. Heckman

\footnotetext{
5 That is, if labor force participation for each cohort were an increasing function of age, then those in the labor force at the start of their lives would remain in and be joined later by others with no labor market experience. If, on the other hand, labor force participation were a decreasing function of age, women would exit from the labor force. A bimodal configuration would require first an exit and then an entrance of those exiting most recently.
} 
and Willis (1977), among others, have made extensive use of these panel data to analyze the nature and determinants of life-cycle labor force participation. While the determinants of life-cycle labor force participation continue to be elusive, its nature has become decidedly clearer.6 The two panel studies (NLS and PSID) have provided distributions of the actual percentage of a woman's married life-time spent in the labor force. For cohorts born from 1922 to 1932 this distribution is not center weighted, as would be impied by the homogeneity assumption, but is vaguely U-shaped, having a larger mass in the highest than in the preceding decile.

Because these data span a period of rapidly rising labor force participation rates, any distribution of years worked would tend toward the uniform or the fat-tailed unimodal, even if there was considerable underlying heterogeneity.7 Such heterogeneity would, under stable conditions, result in a U-shaped distribution. The increase in partici-

${ }^{6}$ See Heckman and Willis (1979) for a criticism of their "beta-logistic" procedure which assumes constant (conditional) participation probabilities over time. The data indicate, however, that these probabilities change with time, due to true state dependence, to unmeasured variables such as fixed entry costs, or to a changed impact of certain variables, such as number of children, which they treat as constant over time. 7 If women are homogeneous, all have an identical value for the percentage of their lifetime in the labor force, and the density function will have the entire mass at that percentage, generally somewhere between 0 and 1. If, instead, the population of women is heterogeneous and the labor supply function for the cohort is neither rising nor falling with age, the distribution of years in the labor force for a cohort will have one mass at 0 and another 1 . The distribution of individuals between these two masses would depend entirely on the participation rate. If the labor force participation rate is rising with age for the cohort, the density function would have a mass at 0 and then decrease. Therefore even if there was considerably underlying heterogeneity, rising cohort participation rates with age would cause the distribution of years worked to be vaguely uniform. If some of the population had homogeneous labor supply, a mixture of these two distributions would be unimodal and fat-tailed. 
pation arises in part because prior nonparticipants are drawn into the labor market. The greater is this increase in participation, the smaller will be the mass at zero years of experience. The degree to which the population of women is heterogeneous or homogeneous with respect to labor force participation is critical to understanding occupational segregation by sex, wage differentials between men and women, and the responsiveness of women's labor supply to changes in their wage rates.

If women are identical, but there is random variation in the timing of children, then all would be in the labor force the same percentage of their lifetimes, but each would vary labor market entry and exit accordingly. Within such a world, women would have relatively high turnover and would not amass much job-related human capital. Consider instead a world in which women are heterogeneous with respect to labor supply. Women in this labor force would be "stayers" and remain in for rather long durations. A woman who joined the labor force early in life should, if unconstrained, have choosen an occupation and a training path more like that of a man, whose life-cycle labor force participation is generally uninterrupted. If the aggregate female labor force participation rate is increasing over time, women just entering the labor force would come from the pool of previous nonparticipants, and their choice of occupation would depend upon the amount of time they would remain in the labor force.

Thus even with identical participation rates by age, extreme differences in the accumulated experience of women could arise between these two worlds, one of "perfectly homogeneous" and one of "perfectly 
heterogeneous" women. In general the world of heterogeneous women would have the greatest degree of accumulated labor force experience of working women, a higher average wage for currently working women, and an occupational distribution most resembling that for men, ceteris paribus. Analyticil expressions for the average labor market experience of working women in homogeneous and heterogeneous populations will show how experience ratings respond to changes in labor force participation rates.

Two functions are needed in the analysis that follows: a labor force participation rate function that varies with age for each cohort, $L(A)$, and an age structure of the population, $f(A)$. It will be assumed for simplicity that these two functions are stable over time, and therefore that the cross-section and cohort functions are the same. The empirical work of Section 4 relaxes this assumption.

The relationship between labor force participation and age must first be examined. Participation rates for cohorts of married white women in the United States born from 1855 to 1955 have risen with age, as can be seen from the solid lines in Figure 1.8 In cross section, however, the participation rate for married white women has declined with age before 1950 and has had a bimodal shape for the period after (the dotted line in Figure 1 gives 1970 data).

Assume therefore that participation rises with age, as has been the case for white, married cohorts, such that

$$
L=\alpha+\beta A
$$

8 These results are virtually unaffected by adjustments for urbanization and reflect the extraordinary increases over time in the participation rates of adult women. See Goldin 1983. 
Figure 1: Labor Force Participation Rates of Cohorts of White, Married Women, Born 1866 to 1955: Entire United States

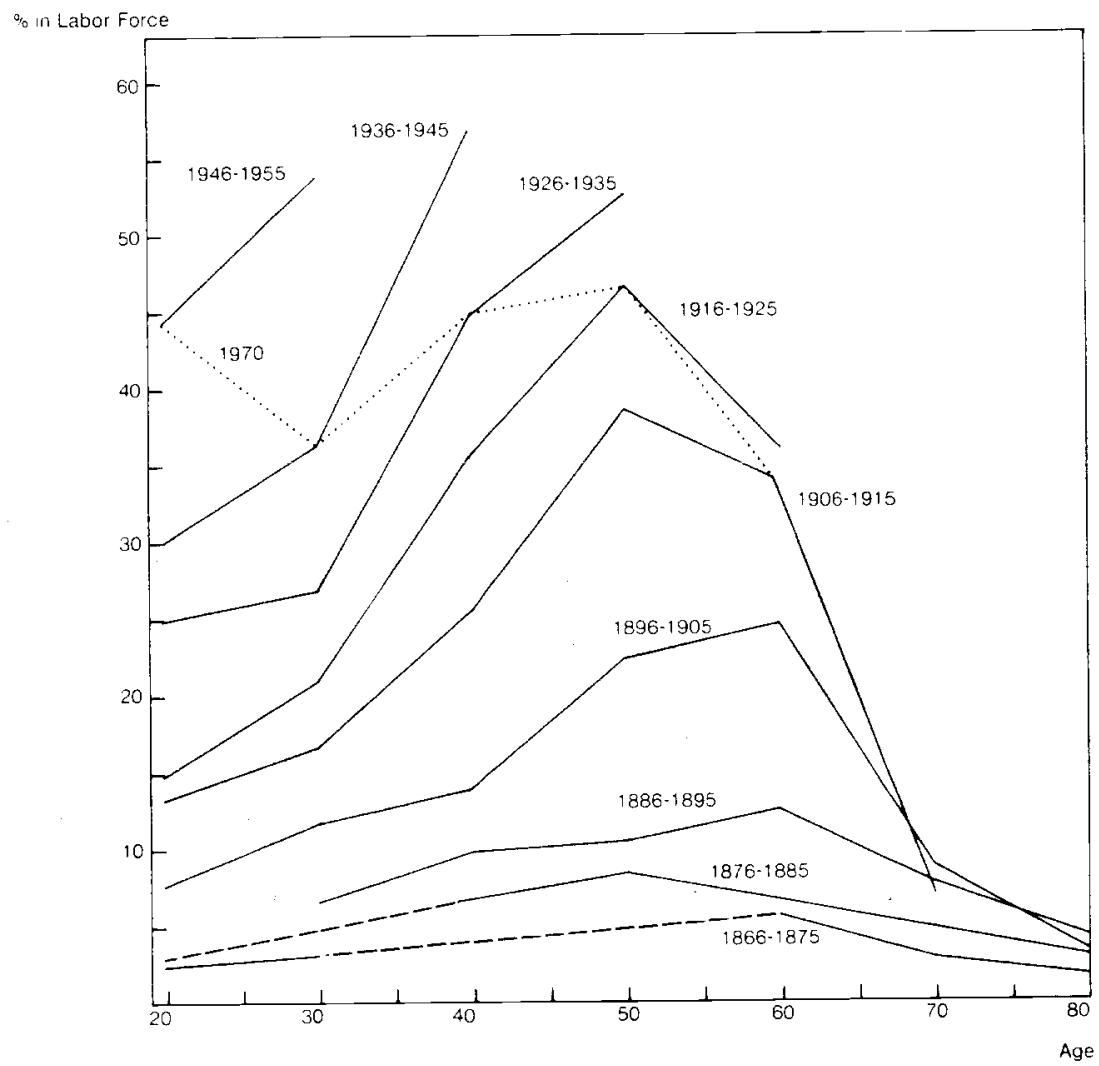

Source: Goldin (1983), derived from population census data. Dashed lines denote missing data. Data for 1890 to 1920 are for native-born women with native-born parents. Dotted line is for the 1970 cross section.

Figure 2: Labor Force Participation Rates (L) by Age (A)

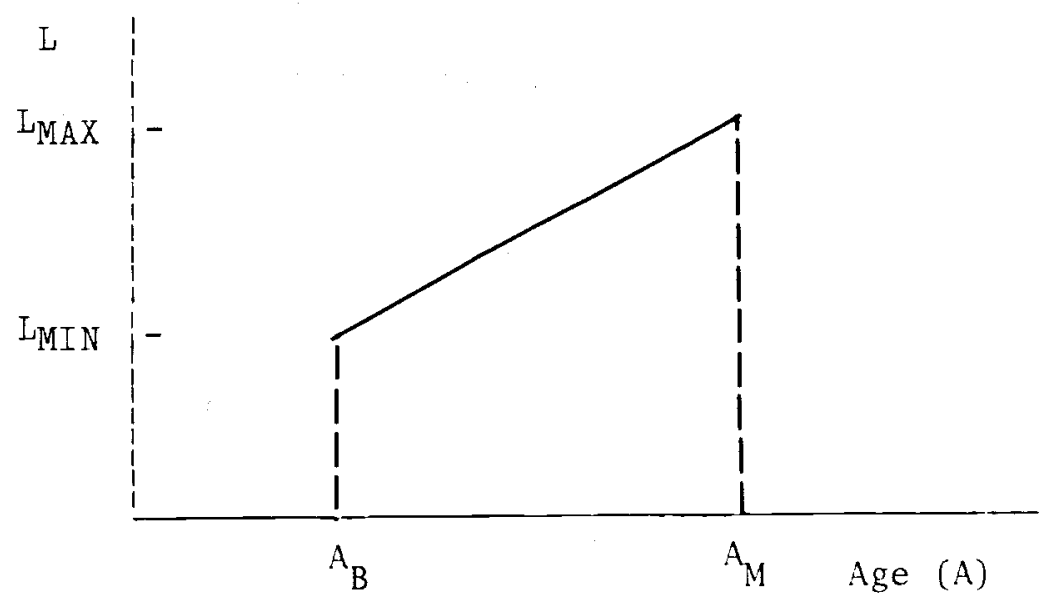


is the labor force participation rate $(0 \leq L \leq 1)$, a linear and positive function of age $(A), B \geq 0$. If $A_{B}$ is the age at which work begins and $\mathrm{A}_{\mathrm{M}}$ is the age at which work terminates for the cohort (the age at retirement or the present age of the cohort if prior to retirement age), then the following expression gives year's experience (EXP) for a working woman of age AM in the homogeneous case

$\operatorname{EXP}=\int_{A_{B}}^{A M}(\alpha+\beta A) d A$

Mean experience for a cross section of such cohorts (EXP*) can be derived in two ways. The first involves multiplying each participation rate by the number of years it is experienced by participants, $\left(A_{M}-A\right)$, and then weighting this quantity by the age distribution of the working population of women. Let the population density function be $f(A), 9$ such that

$$
\int_{B}^{A_{M}} f(A) d A=1
$$

and the global female labor force participation rate be

$$
X=\int_{A_{B}}^{A_{M}}(\alpha+\beta A) f(A) d A
$$

Then the age distribution of the working population is: $\{f(A)(\alpha+\beta A)\} / X$. The average experience of a cross section of working women will be given by 10

$$
\operatorname{EXP}^{*}=\int_{A_{B}}^{A_{M}}(\alpha+\beta A)\left(A_{M}-A\right)\{f(A)(\alpha+\beta A) / X\} d A
$$

9The age distributions of the various cohorts and cross sections will differ if the population is not stable.

10 In the homogeneous case if all women die after $A_{M}$ and the population is stationary, i.e. $f(A)$ is uniform, $\operatorname{EXP}^{*}=(\operatorname{EXP} / 2)$. 
Alternatively, one can weight each of the cohort experience ratings, $\operatorname{EXP}\left(A_{N}\right)=\int_{A_{B}}^{A_{N}}(\alpha+B A) d A$, by the age distribution of the working population to get

$$
\operatorname{EXP}^{*}=\int_{A_{B}}^{A_{M}} \operatorname{EXP}\left(A_{N}\right)\left\{f\left(A_{N}\right)\left(\alpha+\beta A_{N}\right) / X\right\} d A_{N} \quad\left(2^{\prime} \cdot\right)
$$

Intuitively one wants the experience of all cohorts in the cross section weighted by each cohort's contribution to the working population. The weight of each cohort depends on both its proportion in the population and its participation rate, namely $f\left(A_{N}\right)\left(\alpha+\beta A_{N}\right)$, for a cohort at age $A_{N}$.

In the heterogeneous case, year's experience (EXP') of a working woman at age $A_{M}$ is given by

$$
\operatorname{EXP}^{\prime}=\int_{A_{B}}^{A_{M}}(\alpha+\beta A) d A /\left(\alpha+\beta A_{M}\right)
$$

Thus $\operatorname{EXP}^{\prime}=\operatorname{EXP} / L_{\text {MAX }}$, where LMAX $=(\alpha+\beta A M)$, because in the heterogeneous case only L $L_{\text {MAX }}$ fraction of the female population is ever employed, and $\left[1-L_{M A X}\right]$ is never employed over the life-cycle.

Mean experience for the cross section is again obtained by integrating over the working population, and weighting by the age distribution of the working population.

The mean experience of a cross section of heterogeneous women who are currently working is given by

$$
\operatorname{EXP}^{*}=\int_{A_{B}}^{A_{M}} \operatorname{EXP}\left(A_{N}\right)\left\{f\left(A_{N}\right) / X\right\} d A_{N}
$$

where $\operatorname{EXP}\left(A_{N}\right)$ is the experience of a homogeneous cohort of age $A_{N}$, 
because the $L\left(A_{N}\right)$ terms in the numerator and denominator cancel eachother.

The following propositions hold even when labor force participation rates are identical in these two worlds of "perfectly homogeneous" and "perfectly heterogeneous" women:

(1) $\operatorname{EXP}^{\prime} \geq \operatorname{EXP}$ and $\operatorname{EXP} *^{\prime} \geq \operatorname{EXP}^{*}$ : the mean experience of both cohorts and cross sections of working women will be greater in the heterogeneous case;

(2) $\partial \operatorname{EXP} / \partial \beta>0$ but $\partial \operatorname{EXP} / \partial \beta<0$ : increasing the gradient of the labor force participation schedule with respect to age will always increase experience of the cohort in the homogeneous case, but will reduce average experience in the heterogeneous case; and

(3) $\partial \operatorname{EXP} / \partial \alpha>0$ and $\partial \operatorname{EXP} / \partial \alpha \geq 0$ : increasing the intercept will increase experience for the cohort except in the heterogeneous case with $\beta=0$.

The intuition behind these results can be seen more clearly with reference to Figure 2, which gives a linear, upward sloping labor force participation rate schedule. In an extreme version of the homogeneous case, women at each age spend $L(A)$ fraction of that year in the labor force and all are present in the labor force at some time each year. An increase in the tilt of this function will increase the average experience of this population. In the heterogeneous case, however, point L MAX gives the maximum fraction of women in the cohort who are ever in the labor force over the life-cycle. Thus [1-LMAX] gives the fraction whose labor market experience is zero. The steeper is this function, given $L_{M I N}$ or $\alpha$, the greater is the area underneath 
the curve. At the same time, however, the greater is the fraction of individuals vith relative y brief exper ence ar the snaller is the fraction with no experience, who are excluded f'om the EXP' mean. In an extreme example, if $\beta=0$, then $\operatorname{EXP}^{\prime}=\left[A_{\mathbb{M}}-A B\right]$, the maximum possible number of years, and any increase in $\beta$ must reduce EXP'.

The implications of these results for relative wages of women to men are straightforward, if productivity and occupational choice are determined solely on the basis of expected number of years in the labor force.11 For the same configuration of labor force participation rates by age, wages should be higher in the heterogeneous case, because $\operatorname{EXP}^{\prime} \geq \operatorname{EXP}$. If, however, labor force participation rates are increasing over time, particularly with $\partial \beta / \partial t>0$, although possibly even with $\partial \alpha / \partial t>0$, wages can decrease in the heterogeneous case while rising in the homogeneous case.

Further complications can be added if the length of breaks in participation also determines wages and occupations. The implication regarding wages is then ambiguous and would depend on the degree to which labor market training depreciated with time away from the labor force. If depreciation were exponential in time, women in the homogeneous case who enter and exit with much frequency would retain more human capital than would those in the heterogeneous case whose gaps in participation were much greater.

Concern in this paper centers primarily around measuring the

11 The simplest way to view the relationship between experience ratings and relative wages is to assume, as a first approximation, that the wage equations for both men and women are linear in the logs of experience and other variables, such as schooling. 
extent to which women who work in the labor market differ from those who do not work at some particular time. Distributions will be sought for the percentage of time that women have worked in the labor market since marriage or since the time work experience began, both for those currently at work and for those not at work.

3.0 Quantitative Evidence on Life-Cycle Labor Force Participation of White Married Women

3.1 Data Sources

Two types of data provide useful evidence on life-cycle labor force participation: longitudinal or panel studies, in which individuals are reinterviewed over a considerable period of time, and retrospective surveys of work experience gathered at one point in time. The longitudinal data, whose collection was initiated with the NLS and the PSID around 1967, are the most reliable and accurate. The drawbacks of these two longitudinal data files are that they cover only the period since 1967 longitudinally (although that before 1967 is covered retrospectively) and only women born since about 1923, those 30 to 44 years old in 1967, are included.

Also of the panel form are the rich data files of the Social Security Administration (see Ruggles and Ruggles 1977) that have been linked to three data sets: the Current Population Survey, 1973; the Retirement History Survey, 1969 to 1974; and the Internal Revenue Data.12 All of these data sets have the one drawback that certain occupations and various employers were not covered by Social Security

12 These three files are also known as the Exact Match samples because individuals in these data sets have been precisely matched by Social Security number. 
during the entire period under consideration. Domestic service and agricultural workers were covered by Social Security beginning only in 1954 , although restricting the analysis to white women makes these two occupations less troublesome.13

Retrospective answers to questions on work experience are a second type of data giving information on life-cycle labor force participation and can be particularly revealing if they include the work histories of those currently at work and those not currently working. A thorough investigation of various data sets indicates that the earliest micro-level evidence on life-cycle female labor force participation is contained in a somewhat obscure document, Women's Bureau Bulletin \#183, "Women Workers in Their Family Environment" (1941).

The original data in this bulletin pertained to working and nonworking women interviewed in Cleveland in 1939.14 The Women's Bureau attempted to ensure that these were probability samples of working women, as regarded occupation, age, and industry, and cleveland was a fairly representative city with regard to the proportion of its married female population employed in 1940, nearing 20 percent at the lower age brackets and just below 15 percent above age 35 . Because

\footnotetext{
13 A more severe problem arises in the case of government employees, particularly teachers. Various state governments joined the Federal Social Security program in 1951 when amendments to the original Social Security Act made public employees eligible for coverage, and other state and local governments joined when the act was changed again in 1954 and 1956. Approximately 75 percent of all teachers were covered by Social Security in 1979, but it cannot be determined how coverage of all public employees has changed over time with regard to sex and occupation.

14 Various Utah cities were also included in the survey but have not been sampled because of their atypicality.
} 
these data contain unique information and the printed tabulations have contain numerous ambiguities, the originals were located in the National Archives and put in machine readable form.15 The discussion below is based on this data file.

3.2 Evidence on Life-Cycle Labor Force Participation from Women's Bureau Bulletin \#183

The original schedules located in the archives contained the data for women who were working in 1939 and those for women who were not working, in two separate forms. Information for working women had been coded and tabulated by the Women's Bureau in 1940, and the original schedules were then destroyed. Index cards containing the codes were fortunately preserved, as were their definitions. Because the Women's Bureau was primarily interested in working women, the data for nonworking women were not coded and the original schedules for this group exist. A somewhat more detailed set of variables can therefore be obtained for the women not currently working in 1939. Complicating the analysis a bit further is that the Women's Bureau had coded work time for the currently working women in 5 year intervals (e.g., 5 to 10 years of employment in the same occupation, 10 to 15 years in two similar occupations), and therefore precise gaps in employment cannot be located for these women.

The distributions of the percentage of years that women have

15 The bulletin did not distinguish between tabulations of the entire population and those of currently working women; women with continuous work experience were not included in the tabulation of work breaks; and the number of married women in the sample changes from table to table. In short, it is not possible to infer from the tables alone what the population at risk of a particular event was. 
spent in the labor force since beginning work are given in Table 1.16 These data are arrayed by birth cohort, and the focus will be primarily on the older women, whose life-cycles were already near or at completion in 1939. The sample contains 96 women 50-59 years old, 234 women 40-49 years old, and 467 women $30-39$ years old, and is already from a relatively homogeneous group of urban, married women whose spouses were present in 1939.

The substantive finding of Table 1 is that married women currently at work in 1939 had considerably different previous labor market experiences than had those not at work in 1939. For women 40-49 years old in 1939, fully 47 percent had participated in the labor force for over 87.5 percent of the time since they had first worked. Although this number drops to about 26 percent for the oldest age group (50-59 years old), fully 44 percent of them had been in the labor force for 75 percent of the time since they had begun work.

The data for women not currently working (in 1939) are in stark contrast (see Table 1, Part B). The distributions of lifetime work are exact opposites of those for currently working women. Among women 40-49 years old in 1939, 49 percent had worked less than 25 percent of the time since they had their first job and only 1.8 percent had worked over 87.5 percent of the time. For those 50-59 years old the

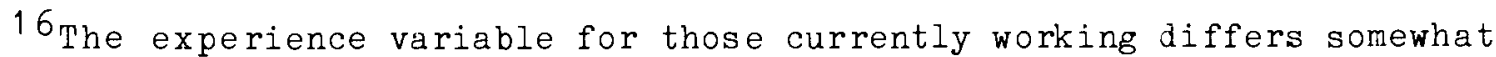
from that for those not currently working. For those working in 1939, the original surveys were destroyed and the codes, constructed by the Women's Bureau to summarize these schedules, were used. These codes grouped work experience by years and by job continuity. The midpoints of these groups were used, e.g. 7.5 years for 5 to 10 years. For the sample of nonworkers, a precise measure of years of employment was available from the original schedules. 
Part A: Women in the Labor Force in 1939

\% Years Worked Since

Beginning Work for

Age in 1939:

Percentage Distribution

Currently Working

Birth Cohort:

Married Women ${ }^{a}$

$$
\begin{gathered}
0-0.125 \\
0.125-0.250 \\
0.250-0.375 \\
0.375-0.500 \\
0.500-0.625 \\
0.625-0.750 \\
0.750-0.875 \\
0.875-1.000
\end{gathered}
$$

$$
\text { 30-39 }
$$$$
\text { 40-49 }
$$
50-59

1901-10 1891-1900

1881-90

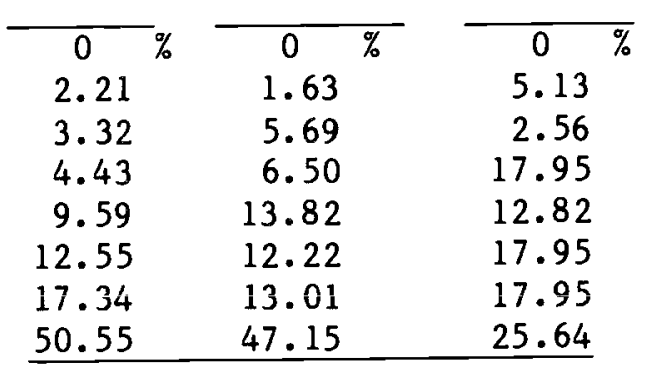

Number of Observations:

271

123

39

Part B: Women Not in the Labor Force in 1939

$\%$ Years Worked Since

Beginning Work for

Not Currently Working

Married Women

$$
\begin{gathered}
0 \\
0-0.125^{b} \\
0.125-0.250 \\
0.250-0.375 \\
0.375-0.500 \\
0.500-0.625 \\
0.625-0.750 \\
0.750-0.875 \\
0.875-1.000
\end{gathered}
$$

\begin{tabular}{rrr}
$0 \%$ & $0 \%$ & $0 \%$ \\
11.73 & 21.62 & 29.82 \\
21.94 & 27.03 & 35.09 \\
29.08 & 19.82 & 21.05 \\
13.78 & 12.61 & 3.51 \\
9.18 & 9.91 & 7.02 \\
6.63 & 4.50 & 1.50 \\
4.59 & 2.70 & 0.00 \\
3.06 & 1.80 & 1.75 \\
\hline
\end{tabular}

Number of Observations:

$196 \quad 111$

57

Source: Manuscripts of Women's Bureau Bulletin \#183 (1941). See text.

a Married, spouse present.

b All intervals exclude lower bound and include upper bound. 
percentage who worked less than 25 percent of the time is even higher, 65 percent. It seems clear in using this particular measure of lifecycle labor force participation that women currently in the labor force had worked a substantial percentage of their years since their first employment, but that those who were not currently in the labor market had been infrequent participants all of their lives. These findings are similar to those noted first by Ben-Porath (1973) and later by Heckman and Willis (1977, 1979), but span a far earlier group of cohorts.

Some of this heterogeneity may have been the product of the Depression and may provide the exception and not the rule. Women who had jobs in the 1930 s often maintained them, and those who entered the Depression without jobs stood a poor chance of becoming employed. Despite the peculiarities of the decade preceding the survey, the oldest cohorts in the sample were recounting labor market experiences which extended well before this period, and their life-cycles were only in part affected by the Depression years. But what ever the underlying reasons for this heterogeneity in labor force involvement, measured life-cycle labor force participation is nonetheless relevant to understanding changes in work experience over time.

The lifetime participation measure used in Table 1, the percentage of years worked since beginning work, had been dictated by the surviving information in the records. A better measure would be the extent of participation since the time of marriage. Such information does exist for many of the nonparticipants, but not for those currently working. All of the current nonparticipants in the sample had once 
worked in the labor force, generally before marriage, and Table 2, Part A summarizes their work histories by age. Most, somewhere between 50 and 60 percent, exited with marriage, and only about 25 percent worked both before and after marriage. A small percentage indicated that they had worked only after marriage, however some, particularly in the older age groups, probably worked before marriage but failed to recall such distant events.17 About 10 percent did not indicate when they had married, and therefore the relationship between marital status transitions and the timing of labor force exit could not be ascertained.

Gaps in work experience for those currently working cannot be precisely located and analyzed. Part B of Table 2 summarizes the information that does exist on the continuity of labor force involvement for this group. About one-third, independent of age, had remained in a similar joj without a break in labor force participation since beginning work. Another third had some break in experience but had remained in a similar occupation, and the remaining third experienced both a break in experience and a change in occupation.

Labor market work began not long after school completion for most of the age groups, but for the oldest age group, initial labor market contact was reported to have occurred at a fairly late age, indicating that work must have begun after marriage for many of these women. Alternatively, and as mentioned above, the first instance

17The Women's Bureau apparently believed the data on the age at which work began. "In Cleveland, where 8 percent of today's women workers were not even graduated from the grammar grades, not far from half (43 percent) of these women did not go to work until 18 years of age or older, and a noticeable proportion not until after 25 years" ( .3$)$. 
Table 2

Labor Force Transitions for Married Women, 1939

Part A: Currently Non-Working Women

$$
\text { Mean Birth Year: } 1914 \quad 1904 \quad 1894 \quad 1884
$$

Age: $\underline{20-29} \quad \underline{30-39} \quad \underline{40-49} \quad \underline{50-59} \quad \underline{60+}$

$\begin{array}{llllll}\text { Exit with marriage } & 49.3 \% & 60.7 \% & 62.1 \% & 56.1 \% & 57.1 \%\end{array}$

$\begin{array}{llllll}\text { Work only after marriage } & \text { 5.0 } & 1.5 & 4.5 & 8.8 & 14.3\end{array}$

$\begin{array}{llllll}\text { Work before and after } & 25.0 & 31.1 & 26.1 & 24.6 & 17.9\end{array}$

\begin{tabular}{llllll} 
Not indicated & 20.7 & 6.6 & 7.2 & 10.5 & 10.7 \\
\hline
\end{tabular}

$\begin{array}{lllllll}\text { Number of observations } & 140 & 196 & 111 & 57 & 28\end{array}$

a Some of these women worked prior to marriage but did not list an occupation on the schedule and thus were ambiguous cases.

Part B: Currently Working Women

$$
\text { Age: } \quad \underline{30-39} \quad \underline{40-49} \quad \underline{50-59}
$$

Continuous experience

$$
\text { in similar occupations } \quad 35.8 \% \quad 30.9 \% \quad 35.9 \%
$$

Broken experience

in similar occupations $31.4 \quad 31.7 \quad 33.3$

Broken experience

in different occupations $\quad 32.9 \quad 37.4 \quad 30.8$

Source: Manuscripts of Women's Bureau Bulletin 非83 (1941). See text. 
of labor market contact may have been forgotten. To correct for possible biases due to misreporting the year at which work began, distributions (not included) similar to those in Table 1 were constructed only for women whose reported age at first work was below 30 years. The results do not change substantially for women under 50 years old. But women in the oldest age group showed a far lower percentage working over 87.5 percent of their years since beginning work, although 54 percent had still worked over 62.5 percent of these years. Thus misreporting and poor recall may overstate the percentage of time worked since the first job for older women.

The measure actually being sought for lifetime labor force participation is the percentage of time worked since marriage. This measure is the statistic most commonly employed to explore the life-cycle labor force participation of married women, presumably because women spend most of their adult unmarried years in the labor force. Including years before marriage flattens out the total distributions, causing them to be more uniform. The rather non-uniform distributions in Table 1, Parts A and B for life-cycle labor force participation imply an even stronger degree of heterogeneity within the married years.

What accounts for the different life-cycles of the participants and the nonparticipants? A detailed analysis of the determinants of these persistent differences is constrained by the variables in the survey. While these are a limited set of variables, they concern predetermined characteristics, such as education and first occupation.

Pooling the two sets of data, those of the workers and the nonworkers, allows estimating equations to explain current work status 
and the percentage of years worked since work began. Table 3 gives two logit equations, one for WORK ( $1=$ in the labor force in 1939) and another for PERCENT, (experience/age - age at which work began). Cross-tabulations indicate that workers had more education than nonworkers, were younger, began work at an older age, and were less likely to have begun work in a manufacturing job. The regression on wORK adds important new results: A woman's first occupation affects later work experience independent of years schooling and the age at work entry, and beginning in a manufacturing job reduces the probability of later work by about 13 percentage points. Because the omitted occupation is "unskilled," it appears that women who persisted in the labor market the greatest fraction of years since work began were both those who were initially in highly paid jobs and those who began in low paying jobs. The absence of information on husband's and other family members' income, as well as non-labor income, prevents a complete understanding of the role of first occupation.

The regression explaining PERCENT, the percentage of time worked since work began, was run across two samples, the original pooled sample and a subsample of women whose first work experience occurred prior to age 31. The results do not differ markedly, and only those from the full sample are given. The important findings again concern the role of first occupation, independent of education and the age at which work began. Beginning in a sales or manufacturing job reduced time spent in the workforce by about 11 percentage points below that in professional and clerical jobs as well as those categorized as unskilled (the omitted group). 
Table 3

Explaining Work Status and Life-Cycle Labor Force Participation in 1939

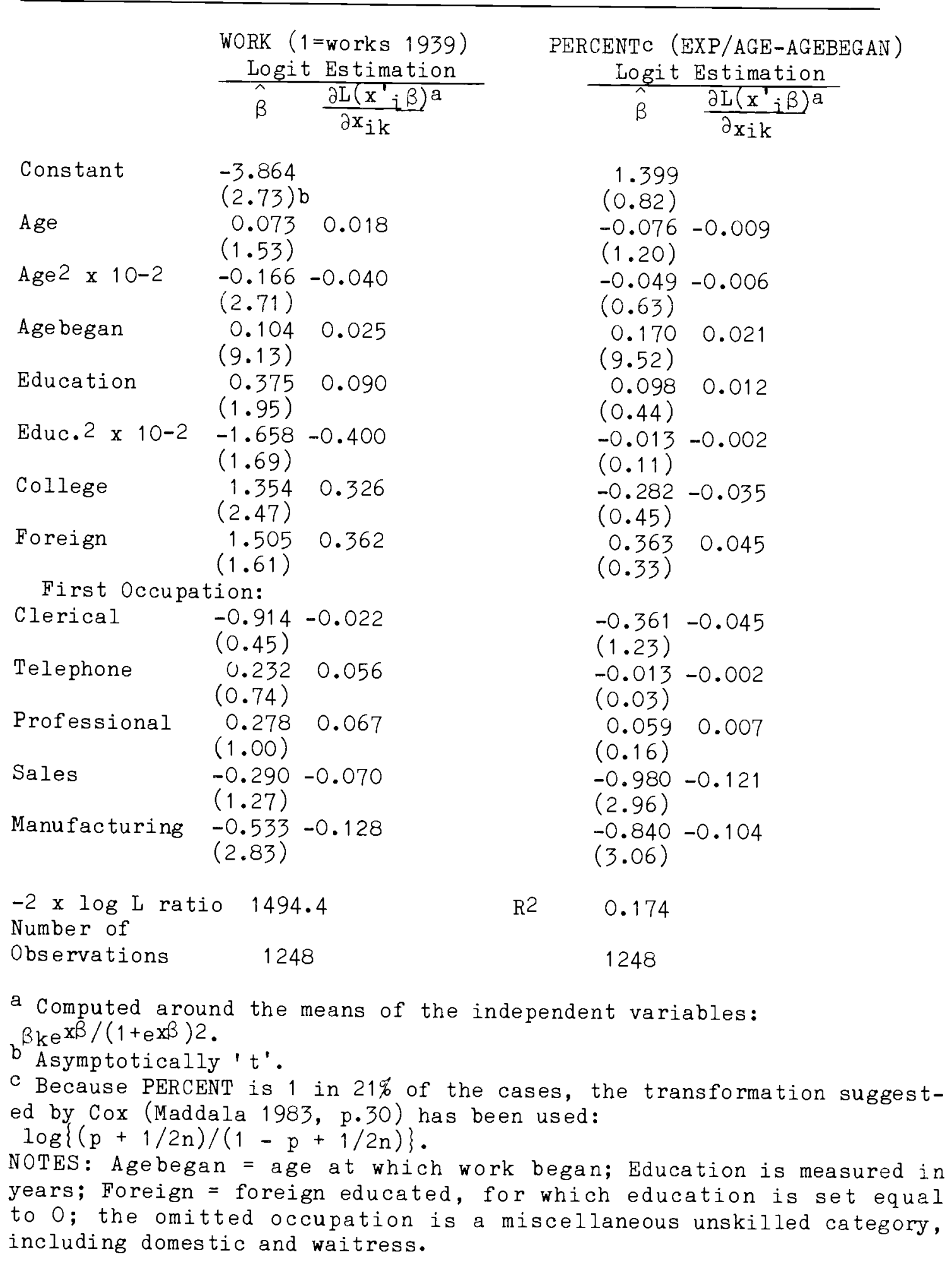


The role of first occupation is important in understanding trends over time in the labor force participation of women. Early in this century the economy's jobs were dominated by those in the agricultural and manufacturing sectors, and women were frequently employed as domestics and operatives. The swift growth of the clerical sector in the mid-twentieth century changed the type of jobs employing women. These occupations differed in fundamental ways: Manufacturing jobs had earnings-experience functions that rose rapidly with time on the job, increased little with education, and reached an early plateau. There is evidence to suggest that earnings fell both with time away from the job and with age itself. The earnings function for clerical work was quite different, rising less rapidly, rewarding formal training, and depreciating little with time away from the job and not at all with age.18 Thus it is not surprising that the women in this sample who began in manufacturing positions exited from the labor force at an early age and those who began in professional and clerical jobs (but not sales which put a premium on youth) persisted. These results provide further evidence that the evolution of work for married women required particular types of occupations or earnings functions.

The data included in this Women's Bureau survey span primarily the 1920s and 1930s, and while the labor force participation rate of married women was expanding at that time, these decades were not ones of remarkable change. The 1950s and 1960s, however, witnessed more rapid increases in participation rates particularly for women

\footnotetext{
18 See Goldin (1984) for a detailed discussion of earnings functions in these two types of jobs.
} 
over age 35.

3.3 Social Security-Retirement History Survey Exact Match Data

The records of the Social Security Administration are a further data source for information on life-cycle labor force participation for cohorts born before those covered by the NSL and the PSID. Of the several data sets that have been linked to them, the Retirement History Survey (RHS) contains the largest number of older women (Henretta and O'Rand, 1980; Irelan 1972; and Mallen, 1974). It is important to bear in mind that this survey was not meant to be a probability sample and that only the wives of survey respondents will be used.19

Furthermore, and as mentioned previously, Social Security coverage varied over time and for certain jobs. Despite these complications, the results of the analyses below will indicate conclusively that female life-cycle labor force participation was characteristically heterogeneous during the 1950s and 1960s. Because these were times of rather large increases in the participation rate of married women, this finding implies that the labor market experience rating of the working population may have fallen over these years, even though the experience of the entire female population must have risen.

The distribution of years worked since 1951 given in Table 4, Part A covers women who were between 54 and 63 years old in 1969, that is 36 to 45 years old in 1951. Labor market work for a year is defined as working for at least two quarters, a definition differing

19 Certain restrictions were placed on the sample for comparability with other data sets. Only white, married women between the ages of 54 and 63 in 1969 who were the first wives of the male respondents in the sample were selected. 
Table 4

Life-Cycle Labor Force Participation From 1951 to 1969

for Cohorts Born 1906-1915

Part A: Distribution of Years Worked Since 1951,

for Women 54 to 63 Years old in 1969

\begin{tabular}{|c|c|c|c|}
\hline Years W & orked & Coho & $\mathrm{rn}:$ \\
\hline From 1951 & to 1969 & $1906-1910$ & $1911-19$ \\
\hline & 0 & $44.0 \%$ & $37.7 \%$ \\
\hline 1 & $<3$ & 19.7 & 10.2 \\
\hline 3 & $<5$ & 5.5 & 6.3 \\
\hline 5 & $<7$ & 5.5 & 6.5 \\
\hline 7 & $<9$ & 4.8 & 4.7 \\
\hline 9 & $<11$ & 4.0 & 4.7 \\
\hline 11 & $<13$ & 3.6 & 5.1 \\
\hline 13 & $<15$ & 5.6 & 5.9 \\
\hline 15 & $<17$ & 4.7 & 5.2 \\
\hline 17 & $<19$ & 5.4 & 4.6 \\
\hline 1 & 9 & 7.5 & 9.2 \\
\hline
\end{tabular}

Number of Observations: $1568 \quad 2065$

Part B: Distribution of Years Worked Since 1951 Conditional on Working in 1953,1960 , or 1965

Cohort Born:

\begin{tabular}{|c|c|c|c|c|c|c|c|}
\hline \multirow{2}{*}{\multicolumn{2}{|c|}{ Years Worked }} & \multicolumn{3}{|c|}{$\underline{1906-1910}$} & \multicolumn{3}{|c|}{$\underline{1911-1915}$} \\
\hline & & \multicolumn{3}{|c|}{ If Work in Year: } & \multicolumn{2}{|c|}{ If Work in } & \multirow{2}{*}{$\begin{array}{r}\text { Year: } \\
1965 \\
\end{array}$} \\
\hline From 1951 & to 1969 & 1953 & 1960 & 1965 & 1953 & $\underline{1960}$ & \\
\hline \multicolumn{2}{|r|}{0} & $0 \%$ & $0 \%$ & $0 \%$ & $0 \%$ & $0 \%$ & $0 \%$ \\
\hline 1 & $<3$ & 1.8 & 1.0 & 0.8 & 2.1 & 1.3 & 0.8 \\
\hline 3 & $<5$ & 9.1 & 1.4 & 0.8 & 5.2 & 3.1 & 1.4 \\
\hline 5 & $<7$ & 5.1 & 4.1 & 8.4 & 7.8 & 3.2 & 6.7 \\
\hline 7 & $<9$ & 7.8 & 4.1 & 6.3 & 6.2 & 3.9 & 7.2 \\
\hline 9 & $<11$ & 6.3 & 7.5 & 8.1 & 6.2 & 7.2 & 8.6 \\
\hline 11 & $<13$ & 6.3 & 9.5 & 6.9 & 6.1 & 12.3 & 10.9 \\
\hline 13 & $<15$ & 9.1 & 17.0 & 13.2 & 8.4 & 15.8 & 12.9 \\
\hline 15 & $<17$ & 6.3 & 14.0 & 14.5 & 9.6 & 14.2 & 13.2 \\
\hline & $<19$ & 18.7 & 17.0 & 17.1 & 14.8 & 12.4 & 12.5 \\
\hline \multicolumn{2}{|c|}{19} & 29.6 & 23.7 & 23.8 & 33.6 & 26.6 & 25.8 \\
\hline \multicolumn{2}{|c|}{ of Observations: } & 396 & 494 & 491 & 562 & 710 & 734 \\
\hline
\end{tabular}

Source: Retirement History Survev- Social Security Administration Exact Match Tapes.

a "Work" in a year is defined as $>2$ quarters of paid employment during that year. 
from that used above but similar to that used in analyses of the NIS and PSID retrospective portions.20 The distribution of years worked is similar to both the NLS sample (Heckman and Willis 1979) and a labor force weighted average of the 1939 data in Table 1. A substantial mass forms around $O$ years, and a sudden upturn occurs at the maximum possible, 19 years.

Distinctions between current workers and nonworkers become more obvious by conditioning the distribution on prior work experience in a particular year,. Working in any either 1953, 1960, or 1965 radically alters the distribution, as can be seen in Part $B$. Among the women in the younger age cohort who worked in 1960 , about 70 percent would eventually work over 13 of the total 19 years, that is they would work 70 percent of the period 1951 to 1969 . Fully 48.3 percent of those in the older cohort who worked in 1953 would eventually work 90 percent of the years from 1951 to 1969; 40.9 percent of those working in 1965 would work 90 percent of these 19 years. But of those not working in 1960, 84.7 percent would eventually work fewer than 5 years; 64.3 percent would not participate at all (defined as never working two quarters in any one year).

${ }^{20}$ Labor force participation rates from 1951 to 1969 calculated in this way for the cohort born 1906-1915 are surprisingly similar to the actual rates achieved by this group, although those computed from the Social Security data have sharp breaks reflecting the amendments to the Social Security Act in 1951 and 1956. The computed rates should be somewhat lower than the official participation rates because Social Security coverage is incomplete. The definition of participation imposed on the SSA data must inflate participation somewhat. 


\subsection{Implications of Life-Cycle Labor Force Participation Data}

Labor market experience of working and nonworking married women can be computed directly from the labor force histories in the 1939 sample. Women 40-49 years old and in the 1939 work force had worked 15.71 years since beginning work, while those not in the labor force in 1939 had worked 7.44 years, less than half that time. The figures for the 30-39 year olds are absolutely lower, but are higher as a percentage of years since beginning work, 12.35 years for those working in 1939 and 5.62 years for those not.

Cohort labor force participation rates for women who were born around 1895, and thus were 40-49 years old in 1939, imply from Figure 1 an $\alpha$ of about 0.02 and a $\beta$ of about 0.0027 , the two parameters of equation (1). Equations (2) and (3), functions of these two parameters alone, yield values of $\operatorname{EXP}=2.7$ years and $\operatorname{EXP}^{\prime}=19.0$ years, for the homogeneous and heterogeneous cases respectively $\left(A_{B}=20\right.$ and $\left.A_{M}=45\right)$. The actual values of experience for this cohort are considerably closer to the perfectly heterogeneous than the perfectly homogeneous case, which is consistent with the life-cycle labor force participation of current participants in Table 1.

The construction of aggregate experience ratings requires an assumption about the distribution within the working population of the two types of individuals, heterogeneous and homogeneous. Define a heterogeneous individual as one who has spent more than 62.5 percent of her years since beginning work in the labor force. Using this definition, the data in Table 1 indicate that 72 percent of the women 40-49 years old were heterogeneous. A weighted average of the two 
experience ratings for this cohort is 14.5 years, reasonably close to the actual one of 15.71 , which includes years worked before marriage. The homogeneous and heterogeneous experience ratings for the 30-39 year old cohort are 2.7 and 14.2 respectively, given $\alpha=0.02$ and $\beta=0.0049$. The weighted average, once again using the definition of heterogeneity as more than 62.5 percent, is 10.2 , roughly comparable to the actual figure of 12.35, again considering the average number of years worked before marriage.

Labor market experience for all cohorts of women born from 1875 to 1925 can be estimated using this technique across the years 1900 to 1980, as has been done in Table 5. The two parameters of the labor force equation ( $\alpha$ and $\beta$ ) have been approximated from the data underlying Figure 1; the heterogeneous proportion of the current labor force at each age, assumed to be stable over time, is given by the 1939 data (which are consistent with the Social Security data).

The experience ratings simulated in this manner for the currently working population increase little over this long time period, despite substantial gains in labor force participation (see Table 1). For 40-49 year olds, years of work experience accumulate at 0.43 percent per year from 1920 to 1940 and at only 0.20 percent per year from 1940 to 1970. Across the entire 50 year period the increase for this age group is from 13.3 years to just 15.4 years, and increases for the other age groups are comparable. In the 1950s, when female labor force participation expanded rapidly, experience ratings increased by the smallest percentage, because of the increase in $\beta$ and the substantial proportion of women with heterogeneous labor supply. The 
Table 5

Simulated Life-Cycle Labor Force Experience

for Cohorts of Married Women Working in Year X

Work Experience Ratings of Married Women Age A in Year X

Cohort Age Year Age Year Age Year Age Year $L=\alpha+\beta A$

Born Year \begin{tabular}{lllllllllll}
$20-29$ & $X$ & $30-39$ & $X$ & 40 & -49 & $X$ & $50-59$ & $X$ & $\alpha$ & $\beta$ \\
\hline
\end{tabular}

\begin{tabular}{|c|c|c|c|c|c|c|c|c|c|}
\hline 1875 & 3.63 & 1900 & 9.53 & 1910 & $\begin{array}{c}13.281^{1920} \\
0.9818 .06^{*}\end{array}$ & 16.28 & 1930 & 0.00 & 0.0012 \\
\hline 1885 & 3.73 & 1910 & 10.08 & 1920 & $1.5518 .90^{14.04} 1930$ & $17=33$ & 1940 & 0.01 & 0.0016 \\
\hline 1895 & 3.77 & 1920 & 10.16 & 1930 & $\begin{array}{c}14.46 \quad 1940 \\
2.6919 .04\end{array}$ & 18.07 & 1950 & 0.02 & 0.0027 \\
\hline 1905 & 3.79 & 1930 & 10.16 & 1940 & $\begin{array}{c}14.671950 \\
4.4818 .63\end{array}$ & 18.68 & 1960 & 0.02 & 0.0049 \\
\hline 1915 & 3.82 & 1940 & 10.25 & 1950 & $\begin{array}{l}15.01 \quad 1960 \\
6.1118 .48\end{array}$ & 19.44 & 1970 & 0.02 & 0.0069 \\
\hline 1925 & 3.85 & 1950 & 10.36 & 1960 & $\begin{array}{c}15.361970 \\
7.5718 .39\end{array}$ & 20.17 & 1980 & 0.02 & 0.0087 \\
\hline
\end{tabular}

* These two numbers, below the line, give the homogeneous and heterogeneous experience ratings for the 40-49 year old age group.

Notes: The homogeneous and heterogeneous cases have been computed with equations (2) and ( 3 ), assuming $A_{B}=20$ years, (that is the mean age at first marriage is assumed to be 20 years), and $A_{\mathbb{M}}=$ the average of the age group:

eq. (2) $\operatorname{EXP}=\alpha(A M-A B)+(B / 2)(A M A M-A B A B)$, and

eq. (3) $\left.\operatorname{EXP}^{\prime}=\operatorname{EXP}\right)\left(\alpha+\beta A_{M}\right)$.

The parameters $\alpha$ and $\beta$ have been derived from the data underlying Figure 1. The computation of the total experience rating assumes that the percentage of women who are "perfectly heterogeneous" by age is:

$20-29$ years $80 \%$, $30-39$ years $80 \%$, $40-49$ years $72 \%$, and

50-59 years 66\%, as derived from the data in Table 1. 
experience rating of the heterogeneous component alone frequently decreased during the decades when $\beta$ increased, (it would have to if $\alpha$ were constant). The average experience rating for $40-49$ year olds increased over the thirty year period 1940 to 1970 , but only because the homogeneous component did (see the disaggregated results).

The aggregate experience rating for the entire population of working women can be obtained by weighting by the age distribution of the female labor force, as in equations ( $\left.2^{\prime}\right)$ or ( $2^{\prime \prime}$ ) and (3'). The aging of the female labor force over this period caused the aggregate experience rating to increase slightly more than the separate entries do by age, and it rose from 9.06 in 1930, to 9.78 in 1940, and reached 10.52 in 1950 , the last year for which all four age groups appear in Table 5 .

These results are consistent with those of Smith and Ward (1983) who estimate life-cycle labor force participation by a different indirect procedure. According to their estimates the labor market experience of working women aged 40 remained roughly constant at 13.5 years from 1940 to 1980, while at same time the work experience of the entire population of women aged 40 rose by over 4 years. 21

In sum, the two data sets giving life-cycle labor force histories for cohorts of women born from the 1880 s to 1910 s indicate substantial (unconditional) heterogeneity in labor force participation. Women who were in the labor force when married tended to remain in and were

$21 \mathrm{~A}$ simple average of the columns in Table 8 for the $30-39$ and $40-49$ age group yields average experience ratings of the working populaticn of 40 year old women that begins at 12.82 years in 1915, increases to 14.03 years by 1935 and then increases gradually to 14.53 across the thirty year period to 1965 . 
$$
-27-
$$

joined by others whose entry expanded the labor force participation rate. An exploration of the determinants of labor force persistence points to the importance of early occupational choice, with women who began in manufacturing jobs tending to exit from the labor force upon marriage. The substantial heterogeneity of labor force participation meant that the accumulated work experience of the currently employed population of married women barely increased during periods of rising labor force participation.

These results have important implications for the relative constancy in the ratio of female to male wages. The relative stability of the experience ratings for the working population of married women suggests that the steadiness of the ratio of female to male wages over much of this century is consistent with the increase in labor force participation during that time period.22
\end{abstract}

22 The constancy of the experience rating of working married women cannot explain the absolute level of the ratio of female to male earnings, but can, at least in part, explain the constancy of the ratio over time. Furthermore the simultaneity of labor force participation and wage rates has not been explored here. 


\section{References}

Ben-Porath, Yoram (1973) "Labor-Force Participation Rates and the Supply of Labor," Journal of Political Economy 81 (May/June) No. 3: 697-704.

Goldin, Claudia (1984) "The Historical Evolution of Female Earnings Functions and Occupations," Explorations in Economic History.

- (1983) "The Changing Economic Role of Women: A Quantitative Approach," Journal of Interdisciplinary History 14 (Spring) No. 4: 707-733.

Heckman, James J. and Robert J. Willis (1977) "A Beta-logistic Model for the Analysis of Sequential Labor Force Participation by Married Women," Journal of Political Economy 85 (February), No. 1: 27-58.

- and (1979) "Reply to Mincer and Ofek," Journal of Political Economy 87 (February), No. 1: 203-212.

Henretta, John C. and Angela M. O'Rand (1980) "Labor-Force Participation of Older Married Women," Social Security Bulletin 43 (August) No. 8: $10-16$.

Irelan, Lola M. (1972) "Retirement History Study: Introduction," Social Security Bulletin 35 (November), No. 10: 3-8.

Maddala, G. S. (1983) Limited-dependent and Qualitative Variables in Econometrics. Cambridge University Press.

Mallen, Lucy (1974) "Women Born in the Early 1900s: Employment, Earnings, and Benefit Levels," Social Security Bulletin 37 (March): 3-24.

Mincer, Jacob (1962) "Labor Force Participation of Married Women." In H. Gregg Lewis, ed., Aspects of Labor Economics. Princeton University Press.

- (1966) "Labor Force Participation and Unemployment." In A. Gordon and M. Gordon, eds. Prosperity and Unemployment. N.Y.

Ruggles, Nancy D. and Richard Ruggles (1977) "The Anatomy of Earnings Behavior." In F. Thomas Juster, ed. The Distribution of Economic Well-Being. National Bureau of Economic Research.

Smith, James P. and Michael P. Ward (1983) "Time Series Changes in the Female Labor Force." Paper presented at the Conference on Trends in Women's Work, Education, and Family Building, Sussex, England.

United States Department of Labor, Women's Bureau (1941) "Women Workers in Their Family Environment," Women's Bureau Bulletin \#183. Washington, D.C. 